\title{
OPPORTUNITIES FOR INNOVATION AND GROWTH IN THE BULGARIAN ECONOMY
}

\author{
V. Pirimova* \\ Department of Economics, University of National and World Economy, Sofia, Bulgaria
}

\begin{abstract}
The main objective of the report is to systematize the potential and available opportunities for increasing the innovations and stimulating through them the economic growth in Bulgaria. The interest in such an analysis is triggered by the great importance of innovation for increasing the competitiveness and export potential of firms and accelerating the rates of economic growth. It is assumed that by 2018 Bulgaria is lagging behind in innovation, according to data from the European Innovation Scoreboard 2018 Bulgaria is defined as a "modest innovator". At the same time, Bulgaria ranks fourth in innovation dynamics, but has an unbalanced innovation system. Similar diversity assessments lead to an analysis of the opportunities for innovation and growth, which are revealed in the report depending on the sectoral structure of GDP, the size structure and the sectoral distribution of the Bulgarian companies and innovations. The results show certain limitations and insufficiently exploited opportunities for innovation in certain economic spheres, existence of retention factors and prerequisites. The main conclusion is the limited possibilities for expected moderate impulse of the innovations and growth in the Bulgarian economy in the coming years. In the study, methods of analysis and synthesis, induction and deduction, and methods of descriptive analysis are used.
\end{abstract}

Key words: economic sectors, economic growth, innovations and innovation firms

\section{INTRODUCTION}

New transformation processes in the economy have been taking place since the beginning of the 21 st century and have accelerated towards the end of the second decade of the century. They are based on technical progress, the intensified development and introduction of information and communication technologies, the gradual progress in robotics and digitalization. These processes induce both economic and structural transformation, bring about substantial changes in the sectoral structure of the economy, and thus redirect the sectoral sources of economic growth. Their implementation increases the importance of investment, especially in modern technologies

\footnotetext{
*Correspondence to: Vera Pirimova, Assoc. Prof., PhD, Department of Economics, University of National and World Economy, Sofia 1700, Bulgaria, v.pirimova@unwe.bg
}

and innovative products, which implies increasing the innovation activity of the companies. They determine higher corporate efficiency, competitiveness and export capabilities, and in this way also play the role of one of the leading factors in accelerating economic growth.

The importance of investment and innovation is highlighted and demonstrated in a vast array of theoretical and empirical analyzes, including the development of traditional and newer trends and models of Keynesian, neoclassical, endogenous theory of economic growth. By applying methodological approaches and methods in them, the contribution to growth is measured and metered in the first place on the amount of the capital investments, and then the attention is focused on the types of investments and the emphasis on the role of innovation. However, to what extent there are conditions and the possible 
PIRIMOVA $V$.

realization of investment and innovation-driven economic growth depends on many factors.

Among these factors, the sectoral structure of the gross value added (GVA), the magnitude (scale of activity) of the majority of the companies, branch and sectoral company and innovation concentration within the boundaries of the individual national economies are of particular importance. The reflected effects of innovative investments are greater, stimulate and stabilize growth, in the presence of commitment and clearer similarity between sectoral parameters of GVA and innovations. Their manifestations are specific at each national, as well as regional, and global level.

Focusing more research on the role and impact of innovation processes on the growth in Bulgaria is particularly necessary in view of the emerging trends in recent years in the EU and Bulgaria. European Commission analyzes show that about two-thirds of the European Union's economic growth over the last decades has been driven by innovation, EU accounts for one-fifth of world R\&D investments (according to the European Innovation Scoreboard 2018). Against this backdrop, there is a certain lag, but also some relatively good positions of Bulgaria on certain indicators. On the one hand, Bulgaria is among the EU countries with the lowest relative share of innovative enterprises - as only $27 \%$ of the enterprises develop effective innovation activity. Because of Bulgaria's innovation gap, the European Commission identifies the country as a "modest innovator" (1). On the other hand, Bulgaria ranks one of the top four (4th) places in the EU in innovation dynamics, achieving the highest growth (of about 30\%) in budget expenditures for innovative activity, although there is an unbalanced innovation system.

In this context, the main objective of the report is the disclosure of opportunities for growth in the Bulgarian economy through the prism of the interconnection between the sectoral structure of GDP and the size and sectoral distribution of firms, investment, innovation and $R \& D$ expenditure in the country. On the basis of this, a similarity or differences can be found as indicative of the untapped potential to dynamize innovation in certain spheres, and hence to achieve higher and lasting increases in aggregate production in the short term.

Trakia Journal of Sciences, Vol. 17, Suppl. 1, 2019
In the study, mainly methods of analysis and synthesis, induction and deduction, and methods of descriptive analysis are used. Statistical data of the World Bank and NSI, also calculated by the author derivative relative indicators are used.

\section{SECTORAL STRUCTURE AND ECONOMIC GROWTH}

As a result, and as an expression of the phased transformation processes, continuous changes in the existing structure of the economy are induced. The leading economic sectors and branches that have a differentiated innovation potential, as well as a certain dynamism in their development, are changing. This determines their different contribution to changes in the aggregate production, to short-term economic growth or cycle. Nonetheless, the views of K. Dervis and S. Ozer are generally shared about the big and growing importance of technology and innovation at the present stage, according to which "Amazing technological breakthroughs and their application in more and more countries and sectors of the economy gave rise to a process of transformation and growth, before which the industrial revolutions in the 18th and 19th centuries pale."(2)

The role for growth of the structure of the economy and its sectoral changes is underlined in a number of studies by representatives of the growth theory. For example, in many of his studies, and especially in the development of the concept for the stages of economic growth, W. Rostow brings sectoral structural changes as the main driver of economic dynamism (3). The structural changes in the economy are considered as a necessary and integral part of the process of economic growth by S. Kuznets (4), (5). However, he does not take up or stand firm on such a categorical position. Because S. Kuznets also develops a theory of long-term cycles (which he calls "long rhythms") on the basis of the summarized results of the study of the dependence between the rates of economic growth and the change of leading industries in the economy (4). In the conditions of more frequent manifestations of uneven growth, under the influence of the modified role of its major and complementary factors, one part of the neoKeynesian growth models are reorientated and converted into cyclical models (see more in (6). In other analyzes, the conclusions do not focus 
on the cycle but relate to the justification of the reported fluctuations reflecting varying and changing speed (rates) of economic growth (see more in (7). In this connection, Robert Heilbroner summarizes that "Nowadays, interest has shifted from finding explanation for these "cycles" of boom and depression to demand an explanation for the unevenness of the dynamics of growth in the long term." (8)

Despite the revealing of ambiguous effects on growth, the role of structural change and its relation to innovation is not rejected but confirmed, considering that they develop in stages, unevenly, with a specific intensity. As a rule, growth drives are concentrated in certain areas and industries that are growing more rapidly and outperforming other industries, especially in terms of more investment and innovation. Growth is stimulated to a greater extent when the sectoral structure of innovation coincides with the structure of the economy, e.g. innovations are mainly orientated in the sector with the largest relative share in GDP. Macroeconomic effects are reinforced when investment increases and is primarily innovative. However, the possibility and the danger of creating or deepening structural imbalances, of opening a break between the economic spheres, which may slow growth or hinder it by triggering reversing processes and crises, should not be underestimated. It is in this connection that P. Salin summarizes that "the crisis is presented in the form of suboptimal use of production factors, as we have already emphasized, because production capacities in some sectors are over-developed." (9). According to L. Grinin and A. Korotaev one of the reasons is that "all spheres in society are connected, so growth in one of them inevitably causes structural strain and deformations in others" (10), which over time can have grown to culminate in the outbreak of crises and recessions. They affect at the beginning and with the most pronounced force the leading spheres and industries, and on the basis of their market commitment in the production system they are then transferred to the other (possibly all) economic spheres. As L. von Mises rightly points out: "Growth can not be directed and controlled because the sectors of the economy are not isolated from each other." (11)
PIRIMOVA $V$.

Potential for higher intensity in their development have the spheres and industries where new technologies are applied, qualitative, competitive or export-oriented products are created, that provide better opportunities for high revenues and profits, investment and innovation on this basis. At the stage in which they become and establish as promising and competitive, they can definitely impulse economic growth but, at the same time, in a bad internal and/or external environment - slow it down, also reduce the depth or prevent an economic downturn. Equally, while the process of renewing and expanding these productions goes, the national economy is more resilient to crisis impulses, and when it reaches certain objective limits it becomes more susceptible to it, more unstable. From here, a tendency to stagnation can be formed, creating conditions for its transformation into a crisis. Periodically, the spheres are rearranged in importance, because the development of those types of activities and productions, which at one stage provide an appropriate field for capital investments, as well as for introduction of relevant new technical and technological principles, is accelerated and then gradually slowed down.

At first covered only a few, the new technological principles are gradually reflected on all other economic spheres and sectors, affecting and stimulating them to a specific extent. Thus, modern IT advances have had the most significant effects on the industrial sector and the financial sector, leading to their diversification and expansion. The improvement of the production equipment and facilities, the computerization of the activities, the automation and the robotization of the production processes have led to a huge increase in the productivity, variety and volumes of the created consumer and investment products. Consequently, the progress in the industry, coupled with advances in communications technology, has led to intensified financial sector development, increased financial services, operations and flows. They have been facilitated and in turn they accelerated the internationalization of production and of the goods, services and capital markets, mainly driven by foreign trade and inflows and outflows of foreign direct investments (FDI). However, it is possible to create conditions for limiting the development 
and potential of other spheres, since, according to Jacques Attali, "an essential part of talents and capital diverts to the financial system itself to the detriment of industry and research." (12) In the event of distortion or disruption of the relationship between financial technologies and innovation and the real sector in the economy, given the greater unpredictability and instability of financial (compared to commodity) markets, growth problems can be induced in perspective (or new crises).

As a result of these processes, the structure of more developed economies is already dominated by the services sector, where the share of the financial and ICT sectors grows, industry as a source of material goods, income and profits, growth or economic downturn, remains in the background. This new structure of the economy has repercussions on investment, innovation and growth in at least two strands:

First, the relative share of the accumulation of physical capital is reduced by the impact of the faster-growing of non-material products (services) and capital. This affects the relationship between the three forms of capital (physical, commodity and money) as well as the dynamism of the economy. Of particular importance is the varying degree of mobility of capital in its separate basic forms. Physical and stock capital is fixed and, therefore, less mobile. The money capital prevailing in the new economy is more mobile, it can be transferred relatively quickly from one market segment to another in searching more profitable application. As a result, there is a process of differentiation of resource provision, an uneven distribution of resources in economic spheres.

Second, the sectoral profile of investment and innovation is changing, which is also influenced by the specific degree of relevance of information and communication technologies (ICT) in the different spheres and sectors. For example, A. Dynkin (13) concludes that new ICTs are becoming more widespread and are spreading more rapidly in the sphere of services, but not in all, and only in certain activities of it. $\mathrm{He}$ found that in the United States at the beginning of the $21 \mathrm{st}$ century of ten high ICTintensive industries in the core funds, eight were related to services. These are, in particular, wholesale trade, business services, education, financial services and insurance, retail, health
PIRIMOVA $V$.

and legal services. Being oriented towards households or firms, they depend more heavily on fluctuations in consumer demand, people's incomes, firms' profits and lending. Furthermore, the range of business and professional services sought and offered by businesses is increasing in connection with the continuous technological and structural complexity of production, the prominent need for more innovation to increase the competitiveness of firms and of the economy. All in all, new technologies are more widespread and further stimulate the development of some service industries. As a result, the problem of rational utilization of intangible assets and factors relating to the quality characteristics of labor and human capital and new organizational and management models is growing. There is a process of radical organizational and technological modernization that encompasses many of the traditional industries and is becoming one of the main structural features of the modern economy.

The manifestations of the restructuring and of the investment-innovation conditioning of the economic growth are specific in the individual countries, including in Bulgaria.

\section{SECTOR STRUCTURE AND SOURCES OF GROWTH IN THE BULGARIAN ECONOMY}

Over the past 30 years, sectoral and branch restructuring of the Bulgarian economy has taken place. It is one of the more significant consequences of the market reforms implemented in Bulgaria and the accompanying processes of privatization, closure or transformation of ownership and activity of state-owned companies, development of entirely new private entrepreneurship. As a result, a transition from almost entirely represented to the GDP state sector to a prevailing private sector was carried out, accompanied by a gradual rearrangement of key sectors in the economy.

Until the beginning of the market transition, the industry have a leading role in the Bulgarian economy, whose output accounts for about half (49\%) of GDP in 1990. With a narrower scope of its total size and the main types of activities carried out, with a relative share of $34 \%$ the service sector is ranked second. The rest of our aggregate production is due to the results of agricultural development. As traditional for the 
Bulgarian conditions, it is relatively well covered and occupies almost one sixth and more specifically $17 \%$ of the country's GDP in 1990. (Figure 1).

Figure 1: Sectoral Structure of Bulgaria's GDP, 1990

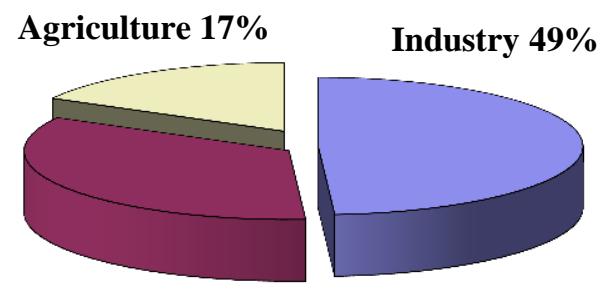

Services 34\%

Figure 1. Sectoral structure of Bulgaria's GDP, 1990 * Sources: World Bank Data (14), (15), 16).

In the coming years occur gradual and one-way changes in the sectoral structure of our country's GDP. They are generated by market reforms, but are also influenced by European and global processes and trends. These changes took place more dynamically in the 1990s and more slowly after the beginning of the 21 st century. The bulk of them is under the influence of the pronounced preference that emerging new private entrepreneurship gives to activities in the service sector. This trend has increased somewhat since 2007, favored by Bulgaria's EU membership and the deepening integration links between Bulgaria and other EU countries, but was also influenced by the impact of the global crisis of 2008-2009 on Bulgaria. As the overall result of the sectoral restructuring in the GDP, decisive significance and the largest share has no longer the industry but the services sector. Thus, by 2017, the service sector occupies a main place and a relative share of over $71 \%$ of GDP, only about a quarter $(24.7 \%)$ of GDP is created in the industry, the share of agriculture, forestry and fishing is only $4.1 \%$ (Figure 2).

Along with the restructuring, the sectoral sources of economic growth are changing, the separate economic spheres and sectors show a differentiated contribution to the achieved real GDP growth (Table 1).

PIRIMOVA V.

Figure 2: Sectoral Structure of Bulgaria's GDP, 2017

Industry 24,7\%

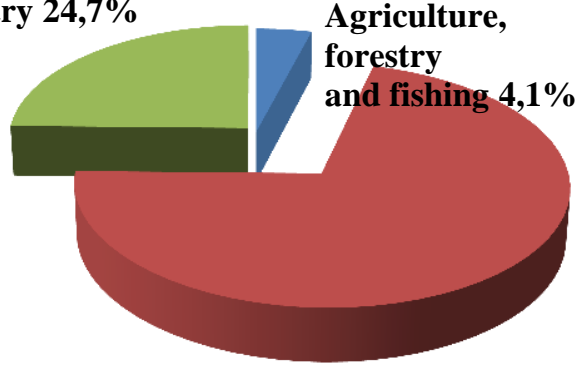

Services $\mathbf{7 1 , 2 \%}$

Figure 2. Sectoral structure of Bulgaria's GDP, 2017

* Sources: World Bank Data (14), (15), 16).

As of 2007-2008, i.e. after overcoming the first crises impulses of market transition and the deep economic and financial crisis of 1996-1997, the development of some industries has stabilized. Among them is the service sector, which not only expands exponentially, but also becomes decisive for GDP growth with a relatively stable, continuously positive increase in output. While its rates are predominantly high, other economic sectors and branches continue to account for fluctuations and larger deviations in their annual positive rates. Along with that, account has been taken of not completely overcome growth disturbances in certain sectors, such as the outstanding in certain years real lagging behind in the mining industry, in agriculture and forestry, in electricity supply. Thus, despite improved conditions, the spread of restorative impulses remains sectorally unbalanced until 2008-2009, with a partial scope, as stabilizing trends primarily concern the service sector.

Externally induced growth disturbances occur in 2008-2009. With a more prominent response (as early as 2006) or deeper declines as major sources of the crisis, which is reflected in a $4 \%$ decline in GDP in 2009, highlights agriculture, forestry and fishing, mining and manufacturing, information and telecommunication, trade, transport, hotels and restaurants, government and education. 
Table 1. GDP Volume index (previous year=100), by economic sectors and groups, 2007-2018 *

\begin{tabular}{|c|c|c|c|c|c|c|c|c|c|c|c|c|}
\hline & 2007 & 2008 & 2009 & 2010 & 2011 & 2012 & 2013 & 2014 & 2015 & 2016 & 2017 & 2018 \\
\hline Total & 107 & 106 & 99 & 102 & 102 & 99 & 100 & 102 & 103 & 103 & 104 & 103 \\
\hline $\begin{array}{c}\begin{array}{c}\text { Agriculture, forestry and } \\
\text { fishing }\end{array} \\
\end{array}$ & 73 & 132 & 91 & 92 & 101 & 93 & 103 & 105 & 93 & 105 & 109 & 99 \\
\hline $\begin{array}{l}\text { Industry (without } \\
\text { Construction) }\end{array}$ & 112 & 102 & 92 & 99 & 107 & 101 & 100 & 104 & 104 & 106 & 104 & 101 \\
\hline Construction & 117 & 115 & 106 & 82 & 97 & 94 & 101 & 97 & 103 & 93 & 104 & 104 \\
\hline \begin{tabular}{|} 
Wholesale and retail \\
trade; repair of motor \\
vehicles and \\
motorcycles; \\
transportation and \\
storage; accommodation \\
and food service \\
activities \\
\end{tabular} & 108 & 97 & 95 & 112 & 103 & 99 & 104 & 101 & 106 & 102 & 103 & 102 \\
\hline $\begin{array}{l}\text { Information and } \\
\text { communication }\end{array}$ & 109 & 174 & 97 & 100 & 112 & 97 & 102 & 101 & 101 & 117 & 106 & 103 \\
\hline $\begin{array}{c}\text { Financial and insurance } \\
\text { activities }\end{array}$ & 133 & 109 & 113 & 125 & 96 & 96 & 93 & 100 & 99 & 107 & 101 & 107 \\
\hline Real estate activities & 105 & 95 & 101 & 104 & 100 & 103 & 98 & 102 & 102 & 106 & 108 & 109 \\
\hline $\begin{array}{c}\text { Professional, scientific } \\
\text { and technical activities; } \\
\text { administrative and } \\
\text { support service activities }\end{array}$ & 118 & 92 & 108 & 93 & 103 & 96 & 103 & 102 & 107 & 102 & 102 & 103 \\
\hline \begin{tabular}{|c|} 
Public administration \\
and defence; compulsory \\
social security; \\
education; human health \\
and social work \\
activities \\
\end{tabular} & 99 & 101 & 101 & 103 & 97 & 103 & 95 & 104 & 101 & 97 & 105 & 104 \\
\hline $\begin{array}{l}\text { Arts, entertainment and } \\
\text { recreation, repair of } \\
\text { household goods and } \\
\text { other services }\end{array}$ & 118 & 134 & 107 & 85 & 116 & 94 & 102 & 101 & 105 & 98 & 105 & 101 \\
\hline \begin{tabular}{|l} 
Adjustments (taxes less \\
subsidies on products)
\end{tabular} & 107 & 106 & 84 & 99 & 101 & 106 & 104 & 100 & 108 & 107 & 102 & 104 \\
\hline $\begin{array}{c}\text { Gross Domestic } \\
\text { Product }\end{array}$ & 107 & 106 & 96 & 101 & 102 & 100 & 101 & 102 & 104 & 104 & 104 & 103 \\
\hline
\end{tabular}

* Sources: NSI data (17)

Industry is the only sector that shows a sustained recovery from the crisis even after 2010 and maintains positive growth rates until the end of the period. For this major contribution has the manufacturing industry, which is influenced by the gradually normalizing domestic and foreign demand and export (in EU and world countries) of industrial production, the advanced stage of reorganization of the activities of the privatized companies and their technical retrofitting. An intensifying effect has the concentration in the manufacturing industry of much of the foreign direct investment entering the country immediately after the peak of the crisis. In contrast to the fast-paced, then substantial outflow of FDI from services, and in particular from financial entrepreneurship, industrial sector attract, for example, over 55\% of FDI in 2010. This trend is also maintained for 2018 , when over $73.5 \%$ of FDI inflows are directed to the manufacturing industry. In recent years, the bulk of domestic (national) investment related also the industrial branches - in them were made about $31 \%$ of the expenditures on acquisition of tangible fixed assets in 2017. On this basis, the industry sector stands out as the most stable source of growth in Bulgaria, although it develops at moderate to low rates.

Activities in the leading service sector (and in particular financial and insurance activities) have been more severely affected by the crisis, with additional year-to-year or multi-year declines taking place even until 2016 inclusive. Their instability can be attributed to the analogous sectoral generator of the crisis in other countries, the contraction of FDI oriented to them. At the same time, after its recovery, and by 2018, the service sector has achieved higher growth rates.

With the highest growth rates and therefore the greatest contribution to our economic growth in 2018 stands out the real estate activities (9\%), financial and insurance activities (7\%) and construction (4\%).

\section{STRUCTURAL FEATURES OF FIRMS, INVESTMENTS AND INNOVATIONS}

The peculiarities of the sectoral and branch structure and the dynamics of GDP are to a large extent a projection of the structural characteristics of investment and innovation. They are closely related to the size, sectoral 
and branch distribution of the companies and their innovative activity. In these several directions, the opportunities for growth of the Bulgarian economy can be revealed.

The large-scale structure of firms is essential to the volume and dynamics of investment and innovation and hence to the rate of economic growth. Smaller firms provide employment and income (to the owner and family members), develop successfully in certain activities and industries, but are financially and economically unsustainable, have limited capital and opportunities for self-growth, find difficult access to bank loans and to European programs and funds. Most of them lack financial and human resources for applied research and innovation. Due to their larger scale of activity, revenues and profits, resource provision and economies of scale, easier access to credit and other sources of funding, the potential for innovation and growth is mostly concentrated in larger companies.

According to the latest NSI data for 2017, the total number of non-financial enterprises in Bulgaria is 406310 . More than 99 percent of all companies in Bulgaria are small and medium-sized enterprises (SMEs), over 92 percent of them are even micro-enterprises (with 1 to 9 employees). Too little remains the working medium-sized companies with 10 to 49 employees $(6 \%)$ and negligible is the share of large companies (with between 50-249 or over 250 employees), a significant part of which are private. With a similar size structure of the companies in the country, the innovation process is hampered by the limited financial, production and technological capacity of the majority of the companies.

To some extent, innovation is hampered by the specific sector-by-branch distribution of companies of varying sizes. The concentration of companies does not coincide entirely with the ranking of the sectors on their relative shares in GDP. Most (36\%) of microenterprises carry out activities in the field of trade and repair, the rest of them focus mainly on "Professional activities and research" and the manufacturing industry. About a quarter (26\%) of small businesses are concentrated in trade and repair, others in the manufacturing (22\%) and construction (10\%). Approximately half of the medium-sized companies are in manufacturing and commerce. Similarly, but with a bigger predominance of the manufacturing industry to trade, is also the
PIRIMOVA $V$. sectoral distribution of large and largest firms (18).

The functioning in the industrial sector of a significant part of the medium and larger enterprises, which are relatively more sustainable, has contributed to the weaker and shorter affecting on the industry sector by the reflection of the global crisis. In the first years after the 2009 crisis, more of the FDI inflows were directed towards this sector, both because of the higher stability of its investments and because foreign investors prefer larger companies, avoid higher-risk SMEs. The sectoral and branch representation of medium and large firms is also indicative of the sectoral concentration of investment and innovation in Bulgaria in recent years. However, the prominent discrepancy with the leading (in GDP) services sector, together with the predominantly small Bulgarian firms, are among the reasons for the weaker effects of innovation dynamics, the more limited potential for long-term and lasting stabilization of growth.

This conclusion is confirmed by the statistics on the amount of investments, innovations and $R \& D$ expenditures undertaken in the country, as well as on their main structural features.

For example, the investments made in recent years in the country are not among the leading and stable sources of growth. The NSI data show that during the period 2008-2017, the companies' expenditures of the tangible fixed assets are not constantly increasing but have unstable, mixed dynamics. They collapse during the crisis year 2009 and in the next 2010, and they decrease in 2016 and 2017. Therefore, by the last 2017 they have been over BGN 11 million less than in the year before the crisis. When classifying and interpreting the investments represented by the tangible fixed assets, whether as domestic (Bulgarian) or external, it should be taken into account that about one third of the FTA costs are actually not made entirely by Bulgarian companies but by companies with over $50 \%$ foreign participation. It is clear from this that the real GDP growth, achieved in 2010-2018, albeit at a low rates, has a different precondition, and cannot be defined as investment-driven growth.

Data on innovations, which are insufficient in terms of volume and have unfavorable 
structure by types and economic sectors, also lead to similar summaries and conclusions.

Due to the already clarified sectoral distribution of the companies, the better innovation potential and the functioning of the bigger ones in the manufacturing industry, the higher share of the innovative enterprises is characterized by the industry $(31.6 \%)$, while in the services sector they are about one-fifth $(22.1 \%)$. These stakes have remained relatively constant over the past few years. A significant part (almost 82\%) of the enterprises identified as innovative are large - they refer to the group of companies with up to or over 250 employees. By comparison, they are far less in the SMEs group; for example, only about a fifth of companies employing between 10 and 49 people are innovative.

Although all types of innovation contribute to the growth of the companies and the economy as a whole, only $19.8 \%$ are enterprises with technological (product and process) innovation, $17.3 \%$ of the companies have undertaken non-technological (organizational and marketing) innovations. Apparently, there are weaker effects, a lag in the innovation conditionality of economic growth, given the overwhelming prevalence of micro and small firms in our country, the limited number of larger companies, the concentration of the innovative ones mainly in areas other than the activities in the leading services sector. Some available unutilized reserves can be revealed by further taking into account innovation in financial and insurance activities (although they account for only about $6 \%$ of GDP), in the context of the continuous registration of new firms and the assumption of their orientation towards innovative products and technologies, opportunities to attract more FDI.

In addition, trends in the dynamics and structural characteristics of R\&D expenditures can be deduced. After a consistently and in some years more substantial increase in $R \& D$ spending, in 2016 and 2017 they sharply decreased. It should be noted that this contraction covers all observed sectors - it is manifested both in enterprises, the public sector, higher education, and partly in nonprofit organizations. At the same time, they do not provide the necessary support for growth because of their unfavorable structural allocation - a huge part of these costs are current, only $9 \%$ are for the acquisition of tangible fixed assets. In sectoral aspect in 2017, the bulk of R\&D expenditures were made in the manufacturing sector, followed in second place by "Creation and dissemination of information and creative products, telecommunications", thirdly, "Professional activities and scientific research". The presentation of enterprises according to their size is similar to the already highlighted trends in innovation. More than $40 \%$ of $R \& D$ expenditure is from large companies with up to 250 employees, nearly $25 \%$ is due to the activity of companies with 50-249 employees, only about $7 \%$ is the share of micro enterprises with 1-9 employees and without employees.

Therefore, the dynamics, the peculiarities of volume and basic structural indicators of investment, innovation and $R \& D$ expenditure reveal insufficient conditions for stimulating and accelerating the economic growth in Bulgaria at this stage.

\section{CONCLUSIONS}

As a result of the analysis, there is a lack of clearer similarity, a certain discrepancy between the sectoral structure of GDP and the leading sector of services, on the one hand, and the size and sectoral distribution of Bulgarian firms, investment, innovation and $R \& D$ expenditure, on the other hand. On this basis, structural parameters of insufficiently exploited innovation opportunities in certain economic spheres were identified, in the group of medium and smaller firms, which appear as retaining factors of innovation and their effects on growth. Some limited opportunities for moderate impetus for innovation and growth in the Bulgarian economy in the coming years can be created by stimulating the development of new firms and their orientation towards innovative products and technologies, increasing domestic investment, attracting more FDI.

\section{REFERENCES}

1. European Innovation Scoreboard 2018, European Union, 2018, https://www.ewivlaanderen.be/sites/default/files/imce/eu_in novatie_scorebord_2018.pdf

2. Dervis K., C. Ozer (2005), A Better Globalization. Legitimacy, Governance, and Reform, Center for Global Development Washington, D.C., p. 18 https://www.cgdev.org/sites/default/files/97 80815717638-Dervis-betterglobalization.pdf

3. Rostow, W. W. (1960), The Stages of Economic Growth: A Non-Communist Manifesto. Cambridge University Press, 
(Delfin-press, Bourgas, 1993, pp. 68-69, p. 71, p. 75)

4. Kuznets S. (1966), Modern Economic Growth: Rate, Structure and Spread, New Haven and London, Yale University Press, 1966

5. Kuznets S. (1971), Modern Economic Growth: Findings and Reflections, Lecture to the memory of Alfred Nobel, December 11, 1971, p. 2, http://www.nobelprize.org/nobel_prizes/eco nomics/laureates/1971/kuznetslecture.html)

6. Pirimova V., (2011), Economic Growth and Economic Cycle in Keynesian Models, Economic Thought, 2011, p. 5

7. Pirimova V., Cyclicality in the economy. Forms, sources, mechanisms, Publishing complex - UNWE, 2014

8. Heilbroner Robert L. (1994), 21st Century Capitalism, W.W. Norton \& Company, (Publishing House „Critique and Humanism“, Sofia, 1997, p. 43)

9. Salin P. (2010), Revenir au capitalisme : Pour éviter les crises, Odile Jacob, 2010, (Sofia, Ciela, 2011, pp. 117-118)
PIRIMOVA $V$.

10.Grinin L., A. Korotaev, (2009), Global Crisis in Retrospectives, Book House "LIBROCOM", M., 2009, pp. 46-47

11.Mises Ludwig von, (2004), The Free Market and Its Enemies, Foundation for Economic Education, 2004, (Institute for Radical Capitalism „Atlas“, Sofia, 2010, p. 100)

12.Attali Jacques, (2008), La crise, et après? (RIVA Publishing House, Sofia, 2009, p. 8)

13.Dynkin A., (2008), World Economy: Forecast till 2020, M., IMEMO RAN, 2008, p. 122

14.http://data.worldbank.org/indicator/NV.SR V.TETC.ZS

15.http://data.worldbank.org/indicator/NV.IN D.TOTL.ZS

16.http://data.worldbank.org/indicator/NV.AG R.TOTL.ZS

17.http://www.nsi.bg/bg/content/2206/бвппроизводствен-метод-национално-ниво

18.http://www.nsi.bg/bg/content/8225/бройна-предприятията 